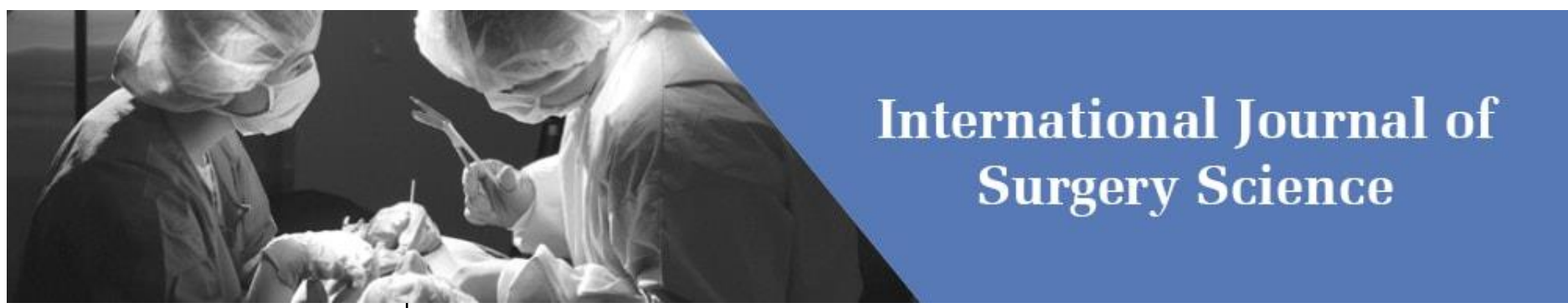

E-ISSN: 2616-3470

P-ISSN: 2616-3462

(C) Surgery Science

www.surgeryscience.com

2021; 5(2): 257-260

Received: 13-02-2021

Accepted: 15-03-2021

Dr. Sachin Jadhav

Dr. VMGMC, Civil Hospital

Campus, Solapur, Maharashtra,

India

Dr. Ritwik Devidas Jaykar Dr. VMGMC, Civil Hospital Campus, Solapur, Maharashtra, India

Dr. Parvat Kashinath Khade Dr. VMGMC, Civil Hospital Campus, Solapur, Maharashtra, India
Corresponding Author:

Dr. Parvat Kashinath Khade Dr. VMGMC, Civil Hospital Campus, Solapur, Maharashtra, India

\section{Clinical study of cholelithiasis in a tertiary care center}

\author{
Dr. Sachin Jadhav, Dr. Ritwik Devidas Jaykar and Dr. Parvat Kashinath \\ Khade
}

DOI: https://doi.org/10.33545/surgery.2021.v5.i2e.702

\begin{abstract}
Background: A cholelithiasis or a gallstone is a stone formed within the gallbladder out of precipitated bile components. The term cholelithiasis may refer to the presence of gallstones, and choledocholithiasis refers to presence of migrated gallstones within bile ducts. Gallstones form as a result of solids settling out of solution. The major organic solutes in bile are bilirubin, bile salts, phospholipids, and cholesterol.

Methods: This is prospective study of 50 patients diagnosed as having cholelithiasis and after obtaining informed written consent of patient. Patients inclusive are all the patients with diagnosis of cholelithiasis (consecutive 50 patients) admitted in tertiary care hospital.

Results and Conclusions: In present study it is concluded that highest age incidence in the $4^{\text {th }}$ decade; age, female gender obesity and diabetes is the commonest cause, pian is the commonest mode of presentation, laparoscopy cholecystectomy is most common treatment of choice, while suture line infection is most common complication of cholelithiasis.
\end{abstract}

Keywords: cholelithiasis, choledocholithiasis, gallstones, gallbladder, cholecystectomy

\section{Introduction}

A cholelithiasis or a gallstones is a stone formed within the gallbladder out of precipitated bile components ${ }^{[1]}$. The term cholelithiasis may refer to the presence of gallstones ${ }^{[2]}$, and choledocholithiasis refers to presence of migrated gallstones within bile ducts. Gallstones form as a result of solids settling out of solution. The major organic solutes in bile are bilirubin, bile salts, phospholipids, and cholesterol ${ }^{[3]}$. The prevalence of gallbladder stones varies widely in different parts of the world. In India estimated to be around 4\% where as in western world it is $10 \%{ }^{[4]}$. It is estimated that at least 20 million persons in the United States have gall stones and that approximately 1 million new cases of cholelithiasis develop each year. Prevalence in Europe is $18.5 \%$ from the autopsy with the lowest prevalence from Ireland (5\%) and the highest from Sweden (38\%). In Australia the prevalence rate varies from $15 \%$ to $25 \%$. Highest prevalence in pima Indian tribe of Arizona. With total and female prevalence of $49 \%$ and $73 \%$ respectively ${ }^{[5,6]}$. Gallstones are rare in Africa with prevalence of less than $1 \%$ and in Japan it has been increased from $2 \%$ to $7 \%$ [5].

\section{Materials and Methods}

Present study was carried out in the department of General Surgery. Dr. VMGMC, SCSMSR general hospital, Solapur. In the present prospective study, total number of surgical patients seen in outpatient department basis of 71752 patients out of which there were 50 cases found. According to these values the incidence of cholelithiasis in our tertiary care center was $0.69 \%$. In this study 50 cases of cholelithiasis were admitted in our tertiary care centre, and after obtaining informed written consent of patient. Patients inclusive are all the patients with diagnosis of cholelithiasis (consecutive 50 patients) admitted in tertiary care hospital. On admission detailed clinical history regarding time of appearance and duration of symptoms were noted. Thorough clinical examination was done. General condition of patient was assessed and noted down. In diagnosis main stress was given on detailed history obtained from patients and following points were noted. The clinical diagnosis of cholelithiasis was ultrasonography, it was clearly showing solitary or multiple gallstones. History and physical examination findings are: Pain was the predominant symptoms in the present study. The commonest site of pain was in the Rt. hypochondrium, and the next commonest site was epigastrium. 
Patients complained of pain radiating to the back, chronic recurring pain, acute onset of pain, pain was colicky in nature, dull aching pain, and nausea/vomiting are the signs and symptoms of cholelithiasis in present study. Patients vomiting was spontaneous, occurred mostly during the attack of pain. In the present study patients had jaundice and dyspepsia. The endoscopic examination in these patients did not reveal any pathology. On ultrasound examination, these patients had gallstones. The dyspepsia was relieved after these patients underwent cholecystectomy. Fever was present in the present study and it was secondary to cholecystitis. These investigations are done in every case to rule-out other associated anomalies and to confirm clinical diagnosis according to severity.

\section{Results and Discussion}

During the period of this study total number of surgical patients seen in our outpatient department basis was 71752 patients out of which there were 50 cases found. This study includes a total of 50 cases that were studied prospectively over a period of 2 years, that were treated as inpatient's basis in our tertiary care center. Well known available literature on cholelithiasis is reviewed. In this study the result of our study is compared with those of well-known authors.

\subsection{Distribution of cases by age group}

Table 1: Age-wise incidence

\begin{tabular}{|c|c|c|}
\hline Age group (years) & Number of cases & Percentage \\
\hline $11-20$ & 1 & $2 \%$ \\
\hline $21-30$ & 5 & $10 \%$ \\
\hline $31-40$ & 9 & $18 \%$ \\
\hline $41-50$ & 17 & $34 \%$ \\
\hline $51-60$ & 11 & $22 \%$ \\
\hline $61-70$ & 6 & $12 \%$ \\
\hline$>70$ & 1 & $2 \%$ \\
\hline
\end{tabular}

There is an increased incidence of cholelithiasis in the 4th and 5 th decade with the peak in the 4 th decade. In my study the youngest patient was 19 years old and the oldest patient is 75 years old.

Table 2: Comparison of age incidence with other studies

\begin{tabular}{|c|c|c|c|c|}
\hline \multirow{2}{*}{ Age group (years) } & \multicolumn{2}{|c|}{ Present study } & \multicolumn{2}{c|}{ Suresh S Karlatt et al. } \\
\cline { 2 - 5 } & No. & \% & No. & \% \\
\hline $11-20$ & 1 & $2 \%$ & 3 & $2.09 \%$ \\
\hline $21-30$ & 5 & $10 \%$ & 9 & $6.29 \%$ \\
\hline $31-40$ & 9 & $18 \%$ & 29 & $26.27 \%$ \\
\hline $41-50$ & 17 & $34 \%$ & 38 & $26.57 \%$ \\
\hline $51-60$ & 11 & $22 \%$ & 30 & $24.48 \%$ \\
\hline $61-70$ & 6 & $12 \%$ & 20 & $13.99 \%$ \\
\hline$>70$ & 1 & $2 \%$ & 9 & $6.29 \%$ \\
\hline
\end{tabular}

In this study, cases fall between 19 and 75 years. There is an increased incidence in the $4^{\text {th }}$ and $5^{\text {th }}$ decade with the maximum incidence in the $5^{\text {th }}$ decade. Similar incidence is seen in the studies of Suresh S Karlatt et al. ${ }^{[7]}$ ( $4^{\text {th }}$ decade $)$.

\subsection{Distribution of cases by sex}

Table 3: Gender-wise distribution

\begin{tabular}{|c|c|c|}
\hline Sex & Number of cases & Percentage \\
\hline Male & 20 & $40 \%$ \\
\hline Female & 30 & $60 \%$ \\
\hline Total & 50 & $100 \%$ \\
\hline
\end{tabular}

In the present study 30 patients were female and 20 patients were male. The present study shows gallstones diseases are a common problem in female population. The female to male ratio is $3: 2$.

Table 4: Comparison of gender distribution with other studies

\begin{tabular}{|c|c|c|c|c|}
\hline \multirow{2}{*}{ Gander } & \multicolumn{2}{|c|}{ Present study } & \multicolumn{2}{c|}{ R Gopi series } \\
\cline { 2 - 5 } & No. & $\boldsymbol{\%}$ & No. & \% \\
\hline Male & 20 & 40 & 21 & $39.6 \%$ \\
\hline Female & 30 & 60 & 32 & $60.4 \%$ \\
\hline Total & 50 & 100 & 53 & $100 \%$ \\
\hline
\end{tabular}

In the present study 30 out of 50 cases were female while the rest 20 were male. R Gopi ${ }^{[8]}$ series showed $60.4 \%$ were female, $39.6 \%$ were male. Similar sex preponderance in the favor of females were noted by R Gopi et al series ${ }^{[8]}$.

\subsection{Aetiology of present case}

In the present study the most common causative factor's in cholelithiasis was obesity and diabetes. In our study number of cases of obesity were 26 patients, and diabetic patients were 15 .

\subsection{Presenting signs and symptoms}

Table 5: Presenting signs

\begin{tabular}{|c|c|c|}
\hline Signs & Number of cases & Percentage \\
\hline Tenderness & 48 & $96 \%$ \\
\hline Guarding & 15 & $30 \%$ \\
\hline Mass & 5 & $10 \%$ \\
\hline
\end{tabular}

Tenderness in the Rt. hypochondriam was present in 48 patients, guarding was present in 15 patients. A positive Murphy's sign was present in 7 patients. A mass was felt in 5 patients. The mass could be due to distention of gallbladder with adherent omentum over laying the inflamed gallbladder.

Table 6: Presenting symptoms

\begin{tabular}{|c|c|c|}
\hline Symptoms & Number of cases & Percentage \\
\hline Pain & 49 & $98 \%$ \\
\hline Nausea/vomiting & 28 & $56 \%$ \\
\hline Jaundice & 7 & $14 \%$ \\
\hline Dyspepsia & 12 & $24 \%$ \\
\hline Fever & 4 & $8 \%$ \\
\hline
\end{tabular}

Table 7: Comparison of presenting symptoms with other studies

\begin{tabular}{|c|c|c|c|c|}
\hline \multirow{2}{*}{ Symptoms } & \multicolumn{2}{|c|}{ Present study } & \multicolumn{2}{c|}{ Ganey's series } \\
\cline { 2 - 5 } & No. & \% & No. & \% \\
\hline Pain & 49 & 98 & 987 & $95 \%$ \\
\hline Nausea/vomiting & 28 & 56 & 576 & $55.6 \%$ \\
\hline Dyspepsia & 12 & 24 & 101 & $10 \%$ \\
\hline Jaundice & 4 & 8 & 222 & $21 \%$ \\
\hline Fever & 4 & 8 & 92 & $9 \%$ \\
\hline
\end{tabular}

Pain was the predominant symptoms in the present study (98\%). The commonest site of pain was in the Rt. hypochondrium, and the next commonest site was epigastrium. 5 patients complained of pain radiating to the back. 48 patients had chronic recurring pain, 2 patients had acute onset of pain, pain was colicky in nature.13 patients had dull aching pain; 33 patients had colicky pain, similar to Ganey series ${ }^{[9]} .56 \%$ (28 patients) of cases in the present series had nausea/vomiting. Patient's vomiting was spontaneous, occurred mostly during the attack of pain. Vomiting in this study was similar to Ganey et al. series ${ }^{[9]}$. In 
the present study 4 patient had jaundice. The endoscopic examination in these patients did not reveal any pathology. On ultrasound examination, these patients had gallstones.

The dyspepsia was relieved after these patients underwent cholecystectomy. The incidence of dyspepsia in present series was $12(24 \%)$. Fever was present in 4 cases in the present study. Fever was secondary to cholecystitis and cholangitis. The fever occurred as a part of Charcot's triad.

\subsection{General physical examination}

The 15 patients were moderately built and nourished, 26 patients were obese. These observations are against the time-honored aphorism that fat people are more prone for this disease. 15 patients were diabetic and 8 patients were using oral contraception or hormone therapy. 4 patients suffered from liver diseases related to alcoholism.

\subsection{Various investigations}

All the patients routine hematological and biochemical investigations were done. The hemoglobin of patients ranged from 8 to $15 \mathrm{gm} \%$. A hemoglobin level of 10 grams was accepted for the surgery. Blood transfusion was given to selected patients to improve the hemoglobin level. 2 cases diagnosed as acute uncontrolled blood sugar level were managed conservatively with IV fluids, nasogastric aspiration, antibiotics, and analgesics. These patients were treated conservatively and were then offered surgery after 6 weeks. Associated medical illness was treated accordingly, before taking the patient to surgery.

Table 8: Comparison of ultrasound findings with other study

\begin{tabular}{|c|c|c|c|c|}
\hline \multirow{2}{*}{ Ultrasound findings } & \multicolumn{2}{|c|}{ Present study } & \multicolumn{2}{c|}{ Alok Sharma series } \\
\cline { 2 - 5 } & No. & \% & No. & \% \\
\hline Stones in gallbladder & 50 & $100 \%$ & 57 & $98.3 \%$ \\
\hline Solitary stone & 12 & $24 \%$ & 15 & $26.3 \%$ \\
\hline Multiple stones & 38 & $76 \%$ & 42 & $73.7 \%$ \\
\hline Thickening of gallbladder & 5 & $20 \%$ & 10 & $17.2 \%$ \\
\hline Mass & 4 & $2 \%$ & 1 & $1.7 \%$ \\
\hline Common bile duct stone & 2 & $4 \%$ & $\mathrm{Na}$ & $\mathrm{Na}$ \\
\hline Empyema & 1 & $2 \%$ & $\mathrm{Na}$ & $\mathrm{Na}$ \\
\hline
\end{tabular}

Ultrasound scanning was done in all patients, all the cases revealed stone in the gall bladder. Gall bladder stones were seen in 50 patients. Out of which 12 were solitary stones, 38 were multiple, thickening of gall bladder was seen in 5 patients, mass detected in 4 patients, common bile duct stone was seen in 1 patients and empyema was seen in only one patient. Many of the features in my study were similar to studies of Major Alok Sharma et al. [10] During laparoscopic cholecystectomy to conversion to open cholecystectomy was due to big mass of the gallbladder.

\subsection{Modalities of treatment}

In the present study 42 patients underwent laparoscopic cholecystectomy, 8 patients underwent open cholecystectomy and 4 patients underwent Endoscopic retrograde cholangiopancreatography due to common bile duct injury and bile leak complication.

Table 9: Type of operation

\begin{tabular}{|c|c|c|}
\hline Type of operation & Number of cases & Percentage \\
\hline Laparoscopic cholecystectomy & 42 & $84 \%$ \\
\hline Open cholecystectomy & 8 & $16 \%$ \\
\hline
\end{tabular}

In the present study 42 patients underwent laparoscopic cholecystectomy, 8 patients underwent open cholecystectomy and 4 patients underwent Endoscopic retrograde cholangiopancreatography for common bile duct injury and bile leak complications.

The conversion rate from lap to open cholecystectomy was $4 \%$. Which was similar to studies of Scott et al. ${ }^{[11]}$ (4.3\%). The conversion rate was $7 \%$ in Schmidt et al. ${ }^{[12]}$

\subsection{Operation and duration of hospital stay}

Table 10: Operating room time with other studies

\begin{tabular}{|c|c|c|}
\hline Type of operation & $\begin{array}{c}\text { Operating room time } \\
\text { Present study }\end{array}$ & $\begin{array}{c}\text { Trondsen } \\
\text { et al. }\end{array}$ \\
\hline $\begin{array}{c}\text { Laparoscopic } \\
\text { cholecystectomy }\end{array}$ & $45 \mathrm{~min}$ & $50 \mathrm{~min}$ \\
\hline Open cholecystectomy & $90 \mathrm{~min}$ & $100 \mathrm{~min}$ \\
\hline
\end{tabular}

The operative room time for open cholecystectomy ranged from $65 \mathrm{~min}$ to $110 \mathrm{~min}$, with approximate average time being 90 min, and laparoscopic cholecystectomy ranged from $30 \mathrm{~min}$ to $70 \mathrm{~min}$, with approximate average time being $45 \mathrm{~min}$. Which were similar to study of Trondsen et al. ${ }^{[13]}$ average $50 \mathrm{~min}$ for laparoscopic cholecystectomy and average $100 \mathrm{~min}$ for open cholecystectomy.

Table 11: Comparison of duration of hospital stay with other studies

\begin{tabular}{|c|c|c|}
\hline \multirow{2}{*}{ Operation } & \multicolumn{2}{|c|}{ Average length of stay (days) } \\
\cline { 2 - 3 } & Present study & Trondsen et al . \\
\hline Open cholecystectomy & 7 & 4 \\
\hline Lap cholecystectomy & 3 & 3 \\
\hline
\end{tabular}

In the present study the average duration of hospital stay were 7 days in open cholecystectomy patients and 3 days in laparoscopic cholecystectomy patients. Similar average duration of hospital stay in open cholecystectomy were 4 days and in laparoscopic cholecystectomy were 3 days according to Trondsen et al. ${ }^{[13]}$ respectively.

\subsection{Postoperative treatment}

All the patients were given IV fluids, Nasogastric aspiration was done, and antibiotics and analgesics were given. Drainage tube was removed between 3 and 5 days based upon the drainage.

\subsection{Types of stones}

According to book reference 45 patients had mixed type of stones, 4 patients had cholesterol stones and only 1 patient had pigment stone.

\subsection{Complications}

Table 12: Pre-operative complications

\begin{tabular}{|c|c|c|}
\hline Pre-operative complications & Number of cases & Percentage \\
\hline Acute cholecystitis & 35 & 70 \\
\hline Chronic cholecystitis & 10 & 20 \\
\hline Empyema of gall bladder & 1 & 2 \\
\hline Mucocoele & 1 & 2 \\
\hline Perforation & 0 & 0 \\
\hline Biliary obstruction & 1 & 2 \\
\hline Acute cholangitis & 1 & 2 \\
\hline Acute pancreatitis & 1 & 0 \\
\hline $\begin{array}{c}\text { Intestinal obstruction } \\
\text { (gallstone ileus) }\end{array}$ & 0 & \\
\hline
\end{tabular}


In this study acute and chronic cholecystitis was the most common preoperative complication, which was 35 and 10 patients had acute and chronic cholecystitis. The percentage regarding was to $70 \%$ and $20 \%$ respectively.

Table 13: Intraoperative complications

\begin{tabular}{|c|c|c|}
\hline $\begin{array}{c}\text { Intra operative } \\
\text { complication }\end{array}$ & $\begin{array}{c}\text { Laparoscopic } \\
\text { cholecystectomy }\end{array}$ & $\begin{array}{c}\text { Open } \\
\text { cholecystectomy }\end{array}$ \\
\hline Bile duct injury & 1 & 1 \\
\hline
\end{tabular}

Table 14: Postoperative complications

\begin{tabular}{|c|c|c|c|}
\hline $\begin{array}{c}\text { Postoperative } \\
\text { complications }\end{array}$ & $\begin{array}{c}\text { Laparoscopic } \\
\text { cholecystectomy }\end{array}$ & $\begin{array}{c}\text { Open } \\
\text { cholecystectomy }\end{array}$ & Total \\
\hline Suture line infection & 1 & 2 & 3 \\
\hline Hemorrhage & 0 & 0 & 0 \\
\hline Retained stones & 0 & 0 & 0 \\
\hline Bile leak & 1 & 1 & 2 \\
\hline Prolonged ileus & 0 & 0 & 0 \\
\hline
\end{tabular}

In the present study 3 patients had suture line infection. 2 patient had post-operative bile leak and 2 patients had bile duct injury which was managed by endoscopic retrograde cholangiopancreatography stenting.

In the present study suture line infection was the most common complication, which was seen in 3 patients. The suture line infection rate in the study of Saxena et al. was 6.3\%. Two patients had bile leak and 2 patients had bile duct injury which was treated by Endoscopic retrograde cholangiopancreatography stenting. In these cases, drain was kept and drain was removed after drain discharged at minimal level or absent.

\subsection{Types of stones}

Table 15: Gross presentation of gallstones postoperative specimen

\begin{tabular}{|c|c|c|}
\hline Type of stones & Number of cases & Percentage \\
\hline Cholesterol stones & 4 & $8 \%$ \\
\hline Mixed stones & 45 & $90 \%$ \\
\hline Pigment stones & 1 & $2 \%$ \\
\hline
\end{tabular}

According to book reference 45 patients had mixed type of stones, 4 patients had cholesterol stones and only 1 patient had pigment stone.

\subsection{Follow up}

There were no complications in the follow up period in any patient. Nothing more can be stated because of limited period of follow up of patients. Patients were advised regarding diet, rest and to visit the surgical OPD for regular follow up for weekly for first month and monthly for next sixth months.

\section{Conclusion}

The incidence of gallstones was highest in the 4th and 5th decades of the life with maximum incidence in the 4th decade. Gallstone's disease is more common in female. The common causes of gallstones were age $\left(4^{\text {th }}\right.$ and $5^{\text {th }}$ decade), female gender, obesity and diabetes. The commonest symptom was pain abdomen and the commonest sign was tenderness in the right hypochondrium. Ultrasonography was the investigation of the choice. It showed multiple gallstones in the majority of cases. The conversion rate from laparoscopic cholecystectomy to open cholecystectomy was 4\%. Acute cholecystitis and suture line infection were the most common preoperative and postoperative complications in our study. Laparoscopic cholecystectomy reduced the number of stay in the hospital, pain and disability as compared to open cholecystectomy. The commonest type of the stone was mixed stone.

\section{References}

1. "Gallstones". NIDDK. November 2013. Archived from the original on 28 July 2016. Retrieved 27 July 2016.

2. Internal Clinical Guidelines Team (October 2014). "Gallstones Disease : Diagnosis and Management of Cholelithiasis, Cholecystisis and Choledocholithiasis. Clinical Guideline 188": 101. PMID 25473723

3. Charles Brunicardi F, Dana K Andersen, Timothy R Billiar, David L Dunn, John G Hunter, Lillian S Kao, et al. Schwartz's Principles of surgery, $11^{\text {th }}$ edition, McGraw-Hill education publication, 2:1401-1414.

4. Tandon R. Diseases of Gall Bladder and Biliary Tract. In: API Textbook of Medicine, Shah SN, ed. 9th ed. Mumbai: API Publications 2012, 911.

5. Cuschieri A. Disorder of the biliary tract. In: Text book of surgery. 4th ed. Philadelphia: Arnold Publication 2002, 375453.

6. Kimberly D, Saunders MD. Pathogenesis of gallstones. Surgical Clinics of North America 1990;70:1197-216.

7. Suresh S Karlatti, Ravishankar Kumar G. Incidence of Various Type of Gallastones in Patients of Cholelithiasis in Belagavi. Belgavi Karnataka. International Journal of Scientific Study. 2016;4(7):21- 23.

8. Gopi R, management of cholelithiasis, a study of 53 cases. Chennai: Govt. Kilpauk Medical Collage, 2019. D42511652.

9. Ganey JB, Johnson PA, Jr, Prillaman PE, McSwain GR, Cholecystectomy: clinical experience with a large series. Am J Surg 1986;151(3):352-7.

10. Sharma A. Towards a safer cholecystectomy - the fundus to porta approach. Indian Journal of Surgery 1997, 141-5.

11. Wexler RS, Greene GS, Scott M. left hepatic and common hepatic ductal bile leaks demonstrated by Tc-99m HIDA scan and percutaneous transhepatic cholangiogram. Clin Nucl Med 1994;19:59

12. Schmidt, Thews G, springer-verlas, Berlin, Germany. Blumgart LH. Gallstones and gallbladder. In: Text book of Surgery of liver and biliary tract. New York: Harcourt Publishers 2007, 617-791. 